\title{
Relational experiences of people seeking help and assessment for subjective cognitive concern and memory loss.
}

Abstract

Objective: To understand the experience of people who seek help for subjective cognitive concern and memory loss, including people not referred for further assessment. To understand the patients' perspective of the medical process of receiving a cognitive assessment. This work is situated within the context of policy priorities for dementia diagnosis.

Methods: Participants with and without dementia were recruited through NHS trusts and community organisations in four regional areas in England. Data were collected using longitudinal qualitative interviews. Transcript data were thematically analysed.

Results: Sample of 41 people (mean 75 years, 25 dementia diagnoses). Interpretative thematic analyses focused on the presence or absence of trust in relational experiences. There were three transition points where trust could be specifically developed or undermined: 1) deciding to seek help; 2) healthcare practitioners' response to help-seeking; 3) process and outcome of assessment. Triggers for help-seeking for subjective cognitive concern were being prompted by family and knowing a relative with dementia. When participants perceived healthcare practitioners' behaviour as dismissive, they had less trust in the outcome of the healthcare encounter. Misunderstandings and absence of trust in assessment processes led to participants stating they did not fully agree with the outcomes of the assessment.

Conclusions: Healthcare practitioners have an important role in supporting people with subjective cognitive concern ensuring patients have trust in assessment outcomes. Where the validity of the assessment process is seen as ambiguous, people can be left dealing with uncertainty, rather than being clear about ways they can manage their condition, situation or status.

Key words: Cognitive assessment, Dementia and cognitive disorders, Primary care, Qualitative methods, Screening and Diagnosis.

\section{Introduction}

Early diagnosis and intervention are key priorities in national dementia strategies (Alzheimer Europe, 2012, Department of Health, 2015; Scholz, 2016). Stated grounds for providing an early diagnosis include enabling more timely access to appropriate treatment, information and support (Department of Health, 2015; Prince, Bryce \& Ferri, 2011). There are an increasing number of case-finding initiatives based on clinical cognitive assessments in hospitals or in routine health checks (Hawkins, 2015; Rubinsztein et al., 2015), but for the majority of people early diagnosis relies on timely helpseeking and appropriate assessment within primary care.

People are confused about which cognitive changes are suggestive of dementia and they may incorrectly attribute clinical signs of cognitive impairment as normal signs of ageing, thereby delaying 
help-seeking (Feldman, Wilcock, Thune-Boyle, \& lliffe, 2017; Perry-Young, Owen, Kelly \& Owens, 2018). Furthermore people may delay seeking help because of dementia-related fears and stigma (Batsch \& Mittelman, 2012; Bunn et al., 2012; Devoy \& Simpson, 2017). This suggests that those who attend primary care are likely to have heightened cognitive concerns which they seek to have acknowledged and addressed.

Primary care general practitioners (GP) are often the first healthcare practitioner (HCP) to formally, or informally, assess a patient's cognitive status (Phillipson, Magee, Jones, Reis \& Skaldzien, 2015). How this consultation is experienced by the patient is likely to be important in establishing their subsequent understanding of, and confidence in, future assessments. Carers and people with dementia underlined how much their first impression of HCPs mattered. If they felt listened to and involved, this had a positive impact on future communication (Karlsson et al., 2015). In dementia care patients and carers saw doctors as needing education in counselling and signposting to services (Foley, Boyle, Jennings, \& Smithson, 2017). This contrasts with GP priorities. GPs focused on good dementia practice through education on diagnosis, disclosure and management of behavioural and psychological symptoms (Foley et al., 2017).

GPs report barriers to making a dementia diagnosis. They may resist undertaking a cognitive assessment because of concerns about conferring stigma related to dementia (Gove, Downs, Vernooij-Dassen, \& Small, 2016); or due to uncertainty about how useful an early diagnosis can be if interventions and support are absent (Fox, Lafortune, Boustani \& Brayne, 2013; Smith et al., 2017). GPs report that organisational structures can make referring to specialised secondary care services complex (Chithiramohan, lliffe, \& Khattak, 2016). Furthermore GPs think that memory clinics are under-resourced and people with mild symptoms may not be a service priority (Chithiramohan et al., 2016). People with memory concerns may also experience depression, anxiety and reduced functionality so further complicating the assessment process (Rotenberg Shpigelman, Sternberg \& Maeir, 2017). Hence the interaction between GP and patient is situated within competing relational personal, social and medical priorities.

People report that the clinical processes of cognitive assessment and potentially receiving a dementia diagnosis is a time of uncertainty, during which they receive limited information and spend long periods of time 'waiting' (Samsi et al., 2014, Campbell et al., 2016). A review exploring the experience of receiving a dementia diagnosis found that the majority of people want to know if they had dementia (Robinson et al., 2011). Carers may also seek a diagnostic assessment for a relative in the hope that labelling cognitive changes will enable access to treatment or facilitate planning for the future (Morgan et al., 2014). This highlights the importance of effective communication in patient/clinician relationships. A limitation is that studies have tended to report on the experiences 
of those who have been referred to memory clinics and who have a diagnosis of dementia or Mild Cognitive Impairment (MCI). The experiences of those who are not referred for further assessment remain under investigated; yet these are a cohort who may benefit from targeted information on lifestyle changes and recognising early signs of dementia.

The individual experience of the initial help-seeking consultation, receiving an assessment, and a possible dementia diagnosis, may be affected by the quality of the person's relationship with the HCP. Good interpersonal skills increase trust between the patient and the HCP (Croker et al., 2013). Trust is a sociological concept based in anticipated and expected behaviours and outcomes in social interactions, which can refer to individual interactions or more broadly to institutional practices (Gilson, 2003; Gille, Smith \& Mays, 2016). Trust is here specified as a dynamic and frangible action, facilitated where a person can place trust in a person presented in a position trusted, here the HCP, to act in their best interests (Bell \& Duffy, 2009; PytlikZillig \& Kimbrough, 2016). Trust is actively constructed within relationships between individuals, between people and events, and between individuals and social structures, such as healthcare systems (Gilson, 2003). Patients are more likely to trust a HCP who they judge as having listened to their concerns, who has empathy and who has technical competence (Murray \& McCrone, 2015; Derkson et al., 2017).

In this paper we draw on the sociological concept of trust to understand the experiences of those who seek help from a primary care doctor for subjective cognitive concerns, but who do not receive a cognitive assessment. People with subjective cognitive concern have an awareness of a memory slip or other cognitive change and this causes them worry (Charlesworth and FitGerald, 2019)). We also report the experiences of patients who have experienced cognitive assessments from diverse health providers, reporting processes and procedures which disrupt their trust in the process of cognitive assessment.

\section{Method}

Data are drawn from a longitudinal interview study which was part of a programme of work investigating: (removed for peer review,). This is a secondary analysis of that interview data. Ethical approval was obtained from (removed for peer review).

\section{Methodology}

We used an interpretive constructivist approach to recognise the layered and relational characteristics of social contexts in data collection and analysis. This approach sees knowledge as constructed through peoples' everyday experiences and co-constructed through shared interactions with others, including the researchers and HCPs and relatives (Schwandt, 1998). This stance is appropriate for more critically exploring a diagnostic event traditionally seen as situated only within 
a biomedical narrative (Bond, 1992). People's explanations for cognitive changes will in practice vary, being contextualised within their lived experiences and not only in medical explanations.

\section{Recruitment}

Participants were recruited from four regions: East Anglia, London, East Midlands and East Yorkshire. Within NHS sites, clinical research staff searched memory clinic lists for people who met the inclusion criteria and sent out study information. People then made voluntary contact with the research team. The research team used the Join Dementia Research database; people matching the study inclusion criteria were emailed or posted study information. To recruit people without a diagnosis of dementia, who were not in contact with memory assessment services, study information was distributed to diverse community groups including hobby clubs, University of the Third Age, church groups, older people clubs and wellbeing centres.

\section{Sample}

Broad inclusion criteria were applied to encourage participation from those with a dementia diagnosis and those who might have subjective concerns about cognitive change and memory but had no dementia diagnosis. Inclusion criteria were: 1) living in the community; 2) willing to share their views on memory; 3 ) able to give informed consent at first interview (opportunity for assent to be provided at subsequent data collection); 4) able to converse in English.

Purposive sampling guided maximum variation in the sample (Patton, 2002). In the main study we recruited people with no memory concerns, with subjective cognitive concern, awaiting a diagnosis, diagnosed with $\mathrm{MCl}$, living with mild to moderate dementia and carers of people with dementia. Within groups we sampled for age and sex differences. Cognitive status was predominantly participant-reported, unless they were recruited through an NHS trust. People were asked directly if they had concerns about memory during demographic data collection.

\section{Data collection}

Semi-structured interviews were carried out between June 2015 and October 2017. The follow-up interview was undertaken after 12-15 months. In the main study, the longitudinal design enabled changes in social activity and independence to be investigated. The longitudinal design enabled further discussion on receiving a diagnosis, specifically with those who had been awaiting a diagnosis at first interview.

Capacity to give consent was assessed before each interview. The protocol required participants to have capacity to give consent at first interview, but a named relative or friend could have given 
assent at second interview. In this sample, all participants were able to give consent at both interviews.

Interviews were guided by a topic guide while flexibly incorporating themes which participants highlighted as important during the interview. The topic guide was developed following a review of literature on the experiences of living with dementia in the community. Topic questions investigated: social attitudes to cognitive concern and dementia, social consequences of memory problems and steps taken in seeking a diagnosis. In this article we report on data relating to perception of memory changes and the process of help-seeking and receiving a cognitive assessment.

Most interviews were carried out in the participant's home ( $n=5$ in alternative setting); sometimes a family member was present but the focus of the discussion remained on the participant. Interviews lasted between 30-90 minutes. The majority of interviews were undertaken by author 1 and author 2. They were supported by three carer co-researchers and five NHS research staff. All researchers were trained and supported by (first author) to maximise quality and consistency in data collection.

\section{Data analysis}

Interviews were professionally transcribed using standardised transcription (Jensen and Laurie, 2016). Transcripts were checked against the audio-recording particularly for omission or incorrect words, then anonymised. Data were stored and managed using NVivo 11.

Thematic analysis was undertaken following the five-step approach advocated by Braun and Clarke (2006). Iterative analysis of the first interviews enabled us to identify themes, select areas to further inform the topic guide and to be aware of when data saturation was occurring in any of the sampling groups. We combined experiential with theoretical analysis to understand how participants constructed the social event of an assessment for subjective cognitive concern. Experiential analyses places the focus on the participant standpoint and how they make sense of the world (Braun and Clarke 2006). In contrast, theoretical concepts are used to guide theoretical analysis (Braun and Clarke 2006). In this secondary analysis; the theoretical analysis was guided by the concept of trust within medical interactions.

The credibility of the results was enhanced in diverse ways. A patient and public reference group provided peer validation. Research team meetings enabled professionals with differing clinical and academic backgrounds to challenge analytical interpretations. Participant validation was not undertaken due to short-term memory loss for many participants and the trajectory of functional concern in dementia. 


\section{Results}

In this sub-study analysis the cohort of 41 participants (49\% female), mean age 75 (54-88 years); 36 participants had second interviews. It was a subset of participants from the larger study (removed for peer review) and represents $33 \%$ of the main study cohort at first interview ( $n=124$ first interview; $\mathrm{n}=104$ second interview). These interviews ( $1^{\text {st }}$ and $2^{\text {nd }}$ interviews $\left.n=77\right)$ were selected for secondary analysis as participants specifically discussed their experience of seeking help for cognitive concern and/or receiving an assessment for objective cognitive impairment. This sample represented groups of people with subjective cognitive concern $(n=7), M C I(n=9)$ and a dementia diagnosis $(n=25)$ see Table 1. The findings for each sub-group are reported here. The full study sample is not included as several participants stated that they were not concerned about their memory and had not instigated help-seeking. Further, some people living with dementia were several years post-diagnosis and had very limited recall of the process of assessment. The credibility of the data appears robust as participants recounted their experiences of help-seeking and assessment in almost identical ways in the follow-up interview, demonstrating the persistence of the narrative.

Some people's journey to a dementia diagnosis appeared to take a linear course from seeing a HCP most usually a GP, to referral to memory services, then receiving a diagnosis, then understanding the diagnosis, going on to share the diagnosis and subsequently living well with dementia. However narratives relating help-seeking and assessment experiences could cover more complex turns. While most initial HCP contacts were made in primary care, one person received initial assessment within secondary care services which she attended in her role as a carer; another experienced initial cognitive assessment through NHS case finding. The interpretative themes reported here are supported by illustrative quotes, given anonymised identifiers covering study number, first interview (T1) or follow-up (T2), sex, age, sample group.

\section{Making a judgement about memory changes}

Making the decision to consult a HCP about cognitive concern-did not appear to happen as soon as the participant acknowledged some change in cognitive function; rather, they weighed up whether this change called for a medical intervention. Many older participants mentioned changes in their memory which they compared to their peers', describing change as an expected part of getting older:

I go back into a room and find I've left a drawer open and I hope that isn't the start of dementia. I hope it's just being elderly. I've chatted with other people and they say they do that, as well. I leave notes for myself and I know my friend does as well. (13005 T1 Female 75-79 subjective cognitive concerns) 
Some participants checked out changes by asking trusted family and friends to say if they thought their memory was worsening.

I have said to my friends that they must tell me if I do these things, because on your own you don't notice it so much so you need somebody to reflect back at you. (13017 T1 Female 60-64 subjective cognitive concerns)

Consequently, some participants were supported by family and friends in seeking help

I was getting a little bit worried because I knew I was repeating things, but I wasn't brave enough to take the first step myself so when my daughters asked if I would go to the doctor I said I would. (16001 T1 Female 60-64 dementia diagnosis)

However relatives' and friends' views on the need to seek assessment sometimes conflicted with those of the participant. In two cases this meant that the participant had not then sought further medical advice:

My sister said "if there was there was nothing to be done, why worry yourself" (13042 T1 Male 65-69, subjective cognitive concerns).

The expertise of the person offering advice on help-seeking was important in conferring trustworthy status on their opinion:

My partner has studied psychology so she is quite aware of things, she thinks that there might be some memory loss, but she thinks it is more likely that I am anxious about memory loss. So this is what I think the GP will think. (11003 T1 Female 50-54 subjective cognitive concerns)

Occasionally a person trusted their own judgement over others, particularly when awareness of their dementia symptoms increased:

People kept saying to me "oh you're fine it is only age" but I felt different in my head I felt different and because I was very aware because of my mum and dad I was aware of all the signs and symptoms, I knew something was not right. (11015 T1 Female 65-69 MCl)

In summary, participants reflected on the nature and cause of any change in cognitive function before seeking help. This, coupled with narratives about fear of dementia, suggests people may 'build up' to going to see a HCP. Help was sought when they were no longer able to offer alternative explanations for memory change, when prompted and supported by family or when their heightened awareness of dementia symptoms increased their concerns. The HCP's initial response importantly shaped how the encounter was constructed then later articulated in participant accounts. 


\section{Professionals' responses to participant help-seeking}

The actions, responses and personal characteristics of the HCP involved in deciding even whether an assessment was necessary shaped the participants' experience of seeking help. Many participants reported that the HCP treated their concerns effectively; referral was prompt and the diagnosis validated their concerns. However some participants did not report a smooth transition, presented here within two categories: 'Persistence -achieving an assessment' and 'Dismissal with no assessment'.

\section{Persistence - achieving an assessment}

Most participants were aware that memory could be tested, but occasionally people had to 'work' at persuading a HCP to take their concerns seriously. Participants could be persistent if their concerns were heightened due to memory loss affecting their activities:

I asked for the test because a strange thing happened. I was on the bus and I thought, "Where the devil am I going? I don't recognise any of this". So I went to the doctor and said that it was the second time that l'd had a funny little turn like that and that something was going wrong. (14005 T1 Female 85-89 dementia diagnosis).

She describes how the doctor was at first dismissive:

He thought it was just my age as I was 88 and getting on a bit. I thought it was more than just forgetfulness, so he said I could have a test, and that's when it was picked up. (11012 T2 Female 80-84 dementia diagnosis).

Although the status of the HCP as 'expert' was important, participant concerns about possible dementia empowered them to make repeated requests for assessment.

I knew he was wrong but you can't tell a consultant that he's wrong can you? I'm just told more more-or-less go away and don't trouble me. He said if you really insist you can come back in a year's time (11012 T2 Female 80-84 dementia diagnosis).

She returned twice more and insisted on further tests after which she received a diagnosis of Alzheimer's disease.

Participants pursued assessment when they said that an early diagnosis would enable them to receive treatment they understood could be helpful: 
I won't be satisfied till I get that test done... best to get the tablets quickly, because when my husband took those tablets it made a lot of difference...done him more good. (11007 T2 Female 85-89 subjective cognitive concerns)

Participants could also pursue action when they or their family considered a diagnosis would enable future planning:

The doctor said not to worry about it, if it's not giving any problems... but daughter said we needed to know ...probably wouldn't have bothered otherwise (13036 T1 Male 65-69 dementia diagnosis).

\section{Dismissed with no assessment}

When the HCP did not respond in ways the participant had expected or even appeared to dismiss their concerns, this breached expectations of respectful behaviour. Some participants reported that they thought worries about memory were dismissed jokily. If rebutted by one doctor, a few participants actively sought a second opinion:

I spoke to another partner[doctor], sometime later and said I understood there was no test, she said she wouldn't have thought of that for me as I seem to be 'with it.' ... that indicates that I was worried about it because otherwise I wouldn't have spoken to the doctor. (13025 T1 Male 80-84 subjective cognitive concerns).

After rebuttals of their attempts to seek assessment the participant then had to make decisions about when to appropriately raise concerns again:

I'Il have to wait until I am a little more obviously demented, before I do [revisit doctors\}...I would still like it, if there was a test, to take it, just to know myself one way or the other (13025 T2 Male 80-84 subjective cognitive concerns).

The HCP's qualifications appeared important in enabling participants to trust their ability to accurately judge whether an assessment was required:

She [doctor] was only a young girl, I think newly qualified and she went to the senior practitioner - I know him and he knows me - and asked his advice. She came back and said, "Do you really want to know what he said?" I said, "Yes, I do". She said "He said, no way, on God's earth has that woman got dementia." (13008 T1 Female 70-74 subjective cognitive concern). 
This participant did not recount the doctor's giving her any further advice or information on reducing risks or monitoring signs, so this encounter left her uncertain about her risk and in a liminal state between actions now open to her:

But, my mother had it, my eldest sister's got it and although at the moment they say it's not hereditary, but is it? (13008 T1 Female 70-74 subjective cognitive concern).

Several layers of trust are embedded then discarded in her account of this event. Initially the newlyqualified doctor sought advice from a senior partner, which could help build the participant's trust in the process. However, when the senior GP then dismisses these worries, this breaches the participant's expectations of what would emerge from sharing their concerns, leaving them instead to recall being in a position of unresolved or even heightened uncertainty.

\section{The assessment process}

How the cognitive function assessment was delivered appeared germane to enabling people to understand and accept the diagnosis. The need to trust both the HCP's skills and also the assessment tool was apparent. When participants perceived clear communication and openness about the process to be absent, this appeared to reduce their trust in outcomes. Results are presented here in two categories: 'Trust and mistrust in assessment processes' and 'Understanding the outcome of the assessment'.

\section{Trust and mistrust in assessment processes}

The professional status of the HCP was noted e.g. 'trainee psychiatrist', suggesting that trust in professional skills was being questioned. If the assessment was not delivered in ways participants saw as 'professional', this reduced trust in, and acceptance of, the validity of the assessment outcome. Limited understanding of the meaning of memory tests scores led to participants 'explaining' a low score as connected with the context of that assessment, rather than reflecting their fluctuating cognitive function:

The tests I did at the clinic I got 85\%, then someone came to my home and I got 95\%, if I had got 95\% before I won't have been through all of this. (13035 T2 Male 75-79 dementia diagnosis)

[Doctor] was not very good as regards putting it over I thought he said count backwards from a hundred missing seven so said 99, 98, 96... I could do it quite easily once I knew what I was doing, it was the way he put it over. (14001 T1 Male 85-89 MCl) 
In one case a lack of understanding of the process led to a participant describing being 'tricked', her distress tangibly reflected here:

They kept firing questions at me I didn't realise the importance of it so I don't feel that I got a fair assessment... and all of a sudden I get landed with, "You've got Alzheimer's!" ... it's hit hard they've labelled me with this.... [crying] condition ... it's not helped, ... it's made me lose my confidence. (14006 T1 Female 75-79 dementia diagnosis)

This participant's distress made it difficult for her to fully relate the process she followed to undergo a cognitive assessment. Nonetheless it makes evident the importance of patient understanding in the assessment process as some participants doubted the assessment outcome and then appeared less able to accept any subsequent diagnosis.

\section{Understanding the outcome of the assessment}

Fully understanding the purpose and procedure of the assessment was important in the participants' understanding and trust in the diagnosis. Not trusting the validity of the assessment made it difficult for people to accept the diagnosis, leaving some in a state of uncertainty:

I had to fill in some forms ... but I don't know whether they were a proper diagnosis. (11019 T1 Female 85-89 dementia diagnosis).

Two nurses came to assess me and they forgot their questionnaire... they wrote a dreadful ungrammatical letter to say they thought I had MCl... I don't know if I'm going to progress, or not, because I don't know how valid that useless diagnosis was. (13024 T1 Female 70-74 MCI diagnosis)

Some participants appeared unclear both about the assessment results and their meaning. Clinical communications were unclear:

[doctor] sent me a letter afterwards but it didn't fully explain (14009 T1 Female 65-69 dementia diagnosis).

Participants sought directly spelt out explanations and conclusive results, even though the HCP may not have considered these appropriate:

I went again this year and did the same test, and failed on the same test, but doctor was quite happy. He said that he didn't think I need go anymore.... I'm happy that I was seen medically, and they are happy with the results. Because I have had an MRI scan but there was nothing showing with memory loss, which I don't understand, really. You'd think there'd be at least some physical sign, wouldn't you. Which is what I don't understand, really. Does dementia begin like this? (14004 T2 Female 75-79 MCI). 
When HCP provided different commentaries participants appeared uncertain of their diagnosis:

I think the cheeky chap put me down as Alzheimer's and then the GP that I worked for years, 'You've never got Alzheimer's,' he says. [laughs - inaudible] 'got loss of memory though'. Mind you, I don't really know the difference between Alzheimer's and dementia (14018 Female 85-89 Dementia diagnosis).

In summary, the participants recall of how the HCP performed the assessment, explained the assessment and any subsequent diagnosis to them affected their confidence and trust in any resulting diagnosis.

\section{Discussion}

Our results provide new understandings about people's experiences of seeking and receiving an assessment for subjective cognitive concerns. Understanding the experiences of the 'worried well', people who a HCP views as not needing a cognitive assessment, is a novel aspect in our results and highlights an area where there is a paucity of research. We found that the help-seeking and assessment processes were constructed social events, shaped by people's expectations of how a HCP might respond to expressed concerns and how an assessment of cognitive function might be conducted. The social concept of trust informed many different types of lived experience across this dataset. Three important transition points, junctions when trust could be developed or undermined were: 1 ) making the decision to seek help; 2 ) the HCP response to help-seeking; 3 ) the process and outcome of assessment. Each are now discussed in the context of our results.

Making the decision to seek help

We found that people displayed agency in monitoring their cognitive function, reviewing their cognition by comparing their current experience with past experiences and comparing their cognitive function to their peers. Help was sought when motivational factors increased; for example if cognitive function impaired daily activities or when emotional responses was heighted by family history and experience of living with someone with dementia. People appeared to trust family and friends' opinions especially when the other was held as an expert. This resonates with a review by PerryYoung et al. (2018) who found that 'advancing factors' which prompted help-seeking were: active reflecting on memory to seek further evidence to support their concerns and exposure to information and others past experiences. People make complex decisions about whether to formally seek help and people gain access to assessment through diverse routes (Begum et al., 2013).

The success of policy initiatives designed to support earlier diagnosis of dementias relies, in part, on people seeking help for cognitive concerns and the GP is most likely to be the first contact (Phillipson 
et al, 2015). However while people may be concerned about the burden of subjective memory impairment very few seek medical help for this particular symptom (Begum, Morgan, Chiu, Tylee, \& Stewart, 2011). Further research could explore whether tailored health advice, provided by a trusted person, and support to self-monitor and recognise worsening symptoms, may help alleviate anxiety and optimise brain health in people with subjective memory concerns.

\section{HCP response to help-seeking}

Trust in the HCP can be especially important when the condition one is disclosing may be stigmatizing (Matusitz \& Spear, 2014). We found that this trust was breached when people perceived that their concerns about cognitive function had been dismissed by the HCP. Key to building trust in medical consultations are the patient's belief about whether their concerns were taken seriously and responded to appropriately (Croker et al., 2013; Gilson, 2003). Occasionally people were concerned that the HCP appeared to dismiss the possibility of a test for dementia, leaving them uncertain about next steps. This has resonance with Bunn's (2012) review on factors that shape the experience of dementia diagnosis which reported that occasionally doctors were slow in recognising symptoms of dementia (Bunn et al., 2012). Furthermore it is suggested that initiatives to increase recognition of mild dementia in primary care may have few or short term effects (Iliffe \& Wilcock, 2017; Pentzek, Vollmar, Wilm \& Leve, 2017). However the presentation of subjective memory impairment in GP practices can be complex, with people presenting with other co-morbidities such as depression, limited functional skills and low self-efficacy (Rotenberg Shpigelman et al., 2017). GPs report challenges around making and communicating a diagnosis of dementia (Philips et al, 2012; Moore \& Cahill, 2013; Chithiramohan et al., 2016). The experience of GPs seems to differ from that of HCP in specialist memory services where a study in UK memory clinics found that all doctors used the word dementia (Dooley, Bass \& McCabe, 2018). There is social complexity within any clinical interaction; relational experiences are shaped by transactions, social norms and expectations of behaviour (Kazimeierczak, 2018). When clinical encounters centre on cognitive impairment doctors may try to 'protect' and patients may try to 'save face'. While inappropriate referral to memory services would not be beneficial, offering advice to those seeking help with subjective cognitive concerns may prevent future delays in help-seeking. In our study no one reported receiving any follow-up advice, but, rather, made personal judgements on when it might be appropriate to revisit a HCP or enlisted the help of family and friends to monitor their cognitive function.

Process and outcome of the assessment process 
During the assessment process, people needed trust in the skills of the HCP delivering the assessment and trust in the reliability of the assessment tool. Given the complexity and diversity of cognitive assessment tools (Larner, 2017) people may well have experienced a variety of tools delivered in different ways, in different settings, by different types of HCP. However our findings are transferable as we found people explained low assessment scores within their accounts of the place of the assessment and HCP's ability to deliver the assessment. The assessment process was perceived as untrustworthy if HCPs displayed 'incompetent' behaviours, such as poor communication, or if they were newly qualified. This absence of trust consequently appeared to reduce people's acceptance of the assessment outcome. Not all people experienced being involved in the process; such reduced agency could reinforce negative assumptions about dementia which connect it to the loss of agency, as an aspect of the social imaginary of the fourth age (Gilleard \& Higgs, 2010). It has been recommended that pre-diagnosis counselling is provided to enable people to better understand the assessment process and possible results for informed decision-making (Guss, 2014; La Fontaine, Buckell, Knibbs, \& Palfrey, 2013). It needs to be evaluated if such counselling is being offered and at which points in the trajectory to diagnosis.

Our results indicated that if people were unclear and anxious about the results of their assessment or how their cognitive impairment might progress, they did not readily accept their diagnosis. Absence of trust in the credibility of the diagnosis can lead to uncertainty (Campbell et al., 2016; Manthorpe et al., 2011; Moniz-Cook et al., 2006) which in turn may place people in a liminal state between being 'a person with memory concerns' but not definitely 'a person with dementia' (Birt, Poland, Csipke, Charlesworth, 2017). Continuing uncertainty about the credibility of a diagnosis can prolong anxiety (Robinson et al., 2011; Samsi et al., 2014). Tolhurst and Kingston argue that 'definition and labelling of the condition' rather than the neurological consequences of dementia initiates the 'status passage' (2013:184). If this is so, careful management of the initial help-seeking consultation, assessment and subsequent diagnosis process is essential. Further work is needed to understand the longer-term health and social impact of ambiguity around the assessment process for both the person with dementia and their family.

\section{Strengths and limitations}

In this study a strength lay in the recruitment strategy enabling us to report on an often hidden group of people: those who seek help for subjective cognitive concerns but who are not offered an assessment and are not referred to memory services. The sample was small but there is evidence that these people continue to have worries which might require monitoring, suggesting there is 
scope for further research with this group and the opportunity to explore relevant health advice on lifestyle and recognising early symptoms of dementia. Our results could be applicable to other settings, as data were drawn from a purposive sample of people across NHS trusts and community settings in different regions of England. However, there is no representation of people from different ethnic backgrounds in the sample and such groups may have distinctly different experiences (Giebel et al., 2017).

In some interviews a family member was present and their presence could impact on accounts given by the research participant. However, it is common for others to be present in qualitative data collection and rare for a person with dementia to be interviewed, or undertake an assessment, completely alone (Nygard, 2006). During data collection the researcher remained focused on the participant and worked to ensure their accounts were brought to the fore rather than those of family members.

We acknowledge that in only interviewing patients we present one interpretation of a diagnostic event and recommend that future research includes the views of all parties, including those making the assessment. Using a constructionist design we sought only the participant's understanding of their clinical diagnosis and future research into diagnostic processes may need to validate clinical diagnoses. In our study validation of participant's ontological sense of their cognitive status was evident within their narratives which were recounted in identical detail at first and follow-up interview. Many participants were interviewed several months since their help-seeking or assessment, so asking about assessment closer to diagnosis, with a broader sample spectrum, may elicit more diversity in reports. Further work should focus on the HCP and patient interaction at this very early stage of a possible dementia journey.

\section{Conclusions}

Narratives from people at various stages in the diagnostic process, including those with subjective cognitive concerns who are not referred for assessment, offers insights into people's judgements on the validity of the informal and formal assessment process, including ways in which trust in the professional skills of the HCP and the reliability of the assessment tools are germane to the person's subsequent trust in the credibility of the assessment outcome. Further research to explore the health practitioner-patient interaction during help-seeking and cognitive assessment, might uncover ways in which trust is breeched or consolidated, potentially helping to improve practice. Dismissing peoples' subjective cognitive concerns in primary care seems to contradict policy initiatives which seek to increase 'case-finding', however it is recognised there needs to be a balance to avoid overreferring. 


\section{References}

Alzheimer Europe. (2012). National Dementia Strategies (diagnosis, treatment and research): country comparisons. Retrieved from www.alzheimer-europe.org/policy-in-practice/countrycomparisons/national-dementia-strategies-diagnosis-treatment-and-research. (accessed 24.01.2017).

Batsch, N.L., \& Mittleman, M.S. (2012). World Alzheimer Report 2012: overcoming the stigma of dementia. London: Alzheimer's Disease International.

Begum, A., Morgan, C., Chiu, C., Tylee, A., Stewart, R. (2012). Subjective memory impairment in older adults: aetiology, salience and help seeking. International Journal of Geriatric Psychiatry, 27, 612620.

Begum, A., Whitley, R., Banerjee, S., Matthews, D., Stewart, R., Morgan, C. (2013).Help-seeking response to subjective memory complaints in older adults: toward a conceptual model. The Gerontologist, 53(3), 462-473.

Bell, L. \& Duffy, A. (2009). A Concept Analysis of Nurse-Patient Trust. British Journal of Nursing, 18, 46-51.

Birt, L., Poland, F., Csipke, E., \& Charlesworth, G. (2017). Shifting dementia discourses from dementia to active citizenship. Sociology of Health and IIIness, 39(2), 199-211.

Bond, J. (1992). The medicalization of dementia. Journal of Aging Studies, 6(4), 397-403.

Braun, V., \& Clarke, V. (2006). Using thematic analysis in psychology. Qualitative Research in Psychology, 3(2), 77-101.

Bunn, F., Goodman, C., Sworn K, Rait, G., Brayne, C., Robinson, L., ... Iliffe, S. (2012). Psychosocial factors that shape patient and carer experiences of dementia diagnosis and treatment: a systematic review of qualitative studies. Plos Medicine, 9(10), e1001331.

Campbell, S., Manthorpe, J., Samsi, K., Abley, C., Robinson, L., Watts, S., ... Keady, J. (2016). Living with uncertainty: mapping the transition from pre-diagnosis to a diagnosis of dementia. Journal of Aging Studies, 37, 40-47.

Charlesworth, G., \& FitzGerald, S. (2019). Fear of dementia: the relationship between mood and subjective cognitive concern. FPOP Bulletin 145, 17-21

Chithiramohan, A., Iliffe, S., \& Khattak, I. (2016). Identifying barriers to diagnosing dementia following incentivisation and policy pressures: general practitioners perspectives. Dementia, 0(0), 116.

Croker, J.E., Swancutt, D.R., Roberts, M.J., Abel, G. A., Roland, M., \& Campbell, J.L. (2013). Factors affecting patients' trust and confidence in GPs: evidence from English national GP patient survey. BMJ Open, 3, e002762. 
Department of Health. (2015). Prime Minister's challenge on dementia: Delivering major improvements in dementia care and research by 2020. Retrieved from.

https://www.gov.uk/government/uploads/system/uploads/attachment_data/file/215101/dh_13317 6.pdf (Accessed 21.08.2018).

Derksen, F., Olde Hartman, T.C., van Dijk, A., Plouvier, A., Bensing, J., Lagro-Janssen, A. (2017). Consequences of the presence and absence of empathy during consultations in primary care: a focus group study with patients. Patient Education and Counselling, 100, 987-993.

Devoy, S., \& Simpson, E.A. ( 2017). Help-seeking intentions for early dementia diagnosis in a sample of Irish adults. Aging and Mental Health, 21(8), 870-878.

Dooley, J., Bass, N., McCabe, R. (2018). How do doctors deliver a diagnosis of dementia in memory clinics? British Journal of Psychiatry, 212(4),239-45.

Feldman, L., Wilcock, J., Thune-Boyle, I., \& Iliffe, S. (2017). Explaining the effects of symptom attribution by carers on help-seeking for individuals living with dementia. Dementia, 16(3), 375-387.

Foley, T., Boyle, S., Jennings, A., \& Smithson, H.W. (2017). "We're certainly not in our comfort one": a qualitative study of GPs' dementia-care educational needs. BMC Family Practice, 18 (1), 66-76.

Fox, C., Lafortune, L., Boustani, M., \& Brayne, C. (2013). The pros and cons of early diagnosis in dementia. British Journal General Practice, 63(612), e510-512.

Giebel, C.M., Worden, A., Challis, D., Jolley, D., Bhui, K.S., Lambat, A., Kampanellou, E., \& Purandare, N. (2017). Age, memory loss and perceptions of dementia in South Asian ethnic minorities. Aging and Mental Health, 10.1080/13607863.2017.1408772, (1-10).

Gille, F., Smith, S., \& Mays, N. (2016). Towards a broader conceptualisation of 'public trust' in health care system. Social Theory and Health, 15(1), 25-43.

Gilleard, C., \& Higgs, P. (2010). Aging without agency: Theorizing the fourth age. Aging and Mental Health, 14(2), 121-128.

Gilson, L. (2003). Trust and the development of health care as a social institution. Social Science and Medicine, 56, 1453-1468.

Gove, D., Downs, M., Vernooij-Dassen, M., \& Small, N. (2016). Stigma and GP's perceptions of dementia. Aging and Mental Health, 20(4), 391-400.

Guss, R. (2014). Clinical psychology in early stage dementia care pathway: Division of Clinical Psychology Faculty of the Psychology of Older People. Leicester: British Psychological Society. Hawkins, J. (2015). Models of dementia assessment and diagnosis indicative cost review. NHS England Retrieved from https://www.england.nhs.uk/wp-content/uploads/2015/09/mods-demntlassessmnt-diag-cost.pdf (last accessed 16.6.18).

Iliffe, S., \& Wilcock, J. (2017). The UK experience of promoting dementia recognition and management in primary care. Zeitschrift für Gerontologie und Geriatrie, 50 (suppl2), 563-567. 
Jensen, E.A., \& Laurie, C. (2016). Doing Real Research: A Practical Guide to Social Research. London UK: Sage Publications Ltd.

Karlsson, S., Bleijlevens, M., Roe, B., Saks, K., Martin, M.S., Stephan, A., ...Hallberg, I.R. (2015). Dementia care in Europeans countries, from the perspective of people with dementia and their caregivers, Journal of Advanced Nursing, 71(6), 1405-1416.

Kazimierczak, K.A. (2018). Clinical encounter and logic of relationality: reconfiguring bodies and subjectivities in clinical relations. Health, 22(2), 185-201.

La Fontaine, J., Buckell, A., Knibbs, T., and Palfrey, M. (2013). Early and timely intervention in dementia : pre-assessment counselling: briefing paper for Faculty for Psychology of Older people and Dementia Action Alliance. Accessed at https://www.dementiaaction.org.uk/assets/0000/5724/BPS_FPOP_DAA_Prediagnosis_Counselling.docx.

Larner, A.J. [Ed]. (2017). Cognitive screening instruments: a practical approach. Springer International Publishing: eBook ISBN 978-3-319-44775-9.

Manthorpe, J., Samsi, K., Campbell, S., Abley, C., Keady, J., Bond, J.,... Iliffe, S. (2011). The transition from cognitive impairment to dementia: older people's experiences. Final report. National Institute for Health Research: Service Delivery and Organisation programme.

Matusitz, J., \& Spear, J. (2014). Effective doctor-patient communication: an updated examination. Social Work in Public Health, 29(3), 252-266.

Moniz-Cook, E., Manthorpe, J., Carr, I., Gibson, G., \& Vernooij-Dassen, M. (2006). Facing the Future: A qualitative study of older people referred to a memory clinic prior to assessment and diagnosis. Dementia, 5(3), 375-395.

Moore, V., \& Cahill, S. (2012). Diagnosis and disclosure of dementia -A comparative qualitative study of Irish and Swedish General Practitioners. Aging and Mental Health, 17(1), 77-84.

Morgan, D.G., Walls-Ingram, S., Cammer, A., O'Connell, M.E., Crossley, M., Dal Bello-Haas, V., ... Stewart, N. (2014). Informal caregivers' hopes and expectations of a referral to a memory clinic. Social Science \& Medicine, 102, 111-8.

Murray, B., \& McCrone, S. (2015). An integrated review of promoting trust in patient-primary care provider relationships. Journal of Advanced Nursing, 71(1), 3-23.

Nygard, L. (2006). How can we get access to the experiences of people with dementia? Scandinavian Journal of Occupational Therapy, 13(2), 101-112.

Patton, M.Q. (2002). Qualitative research and evaluation methods [ $3^{\text {rd } E d .] T h o u s a n d ~ O a k s, ~ C a l i f o r n i a: ~}$ Sage Publications Inc.

Pentzek, M., Vollmar, H.C., Wilm, S., \& Leve, V. (2017). Putting dementia awareness into general practice: the CADIF approach. Zeitschrift für Gerontologie und Geriatrie, 50 (suppl2), 544-547. 
Perry-Young, I., Owen, G., Kelly, S., \& Owens, C. (2018). How people come to recognise a problem and seek medical help for a person showing early signs of dementia: a systematic review and metaethnography. Dementia, 17(1), 34-60.

Philips, J., Pond, C.D., Paterson, N.E., Howell, C., Shell, A., Stocks, N.P.,...Marley, J.E. (2012). Difficulties in disclosing the diagnosis of dementia: a qualitative study in general practice. British Journal of General Practice, Aug; 62(601): e546-e553. doi: 10.3399/bjgp12X653598

Phillipson,L., Magee, C., Jones, S., Reis, S., \& Skaldzien. (2015). Dementia attitudes and help-seeking intentions: an investigation of responses to two scenarios of an experience of early stages of dementia. Aging and Mental Health, 19(11), 968-977.

Prince, M., Bryce, R., \& Ferri, C. (2011). Alzheimer Report 2011. The benefits of early diagnosis and intervention. Retrieved from https://www.alz.co.uk/research/world-report-2011 (Accessed 21.08.2018).

PytlikZillig, L.M., \& Kimbrough, C. D. (2016). Consensus on conceptualizations and definitions of trust: are we there yet? In E. Shockley., T.M.S. Neal., PytlikZillig, L.M., \& B.H. Bernstein [Eds] Interdisciplinary Perspective on Trust: towards theoretical and methodological integration (pp 17-47). Switzerland: Springer International Publishing.

Robinson, L., Gemski, A., Abley, C., Bond, J., Keady, J., Campbell, S., ... Manthorpe, J. (2011). The transition to dementia: individual and family experiences of receiving a diagnosis: a review. International Psychogeriatrics, 23, 1026-1043.

Rotenberg Shpigelman, S., Sternberg, S., Maeir, A.(2017). Beyond memory problems: multiple obstacles to health and quality of life in older people seeking help for subjective memory complaints. Disability and Rehabilitation, 29,1-7.

Rubinsztein, J.S., van Rensburg, M.J., Al-Salihy, Z., Girling, D., Lafortune, L., Radhakrishnan, M., \& Brayne, C. (2015). A memory clink v. traditional community mental health team service: comparisons of costs and quality. British Journal of Psychiatry Bulletin, 36, 6-11.

Samsi, K., Abley, C., Campbell, S., Keady, J., Manthorpe, J., Robinson, L., ... Bond, J. (2014). Negotiating a labyrinth: experience of assessment and diagnostic journey in cognitive impairment and dementia. International Journal of Geriatric Psychiatry, 29(1), 58-67.

Scholz, N. (2016). Need for action on dementia recalled. European Parliamentary Research Service. (Accessed on 21.01.19) www.europarl.europa.eu/RegData/etudes/BRIE/2016/577959/EPRS_BRI(2016)577959_EN.pdf

Schwandt, T.A. (1998). Constructivist, interpretivist approaches to human inquiry. In N.K. Denzin \& Y.S. Lincoln (Eds) The landscape of qualitative research: theories and issues. Thousand Oaks CA: Sage Publications. Pp.221-259.

Smith, T., Cross, J., Poland, F., Brookes, A., Maidment, I., Penhale, B., ... Fox, C. (2017). Systematic review investigating multi-disciplinary team approaches to screening and early diagnosis of dementia in primary care - what are the positive and negative effects and who should deliver it? Current Alzheimer Research, 14. E pub- doi: 10.2174/1567205014666170908094931. 
Tolhurst, E., \& Kingston, P. (2013). Understanding the experience of dementia: Utilising the theoretical insights of 'status passage'. Social Theory \& Health, 11(2), 175-193. 
Table 1 Sample characteristics

(note to reviewers: we had mistakenly included an earlier inaccurate summary table correct one below)

\begin{tabular}{|l|c|c|c|c|}
\hline & Sample & $\begin{array}{l}\text { Subjective } \\
\text { cognitive concerns }\end{array}$ & $\begin{array}{l}\text { Mild Cognitive } \\
\text { Impairment }\end{array}$ & $\begin{array}{l}\text { Dementia } \\
\text { diagnosis }\end{array}$ \\
\hline $\begin{array}{l}\text { Number } \\
\left(2^{\text {nd }}\right. \\
\text { interview*) }\end{array}$ & $\begin{array}{c}41 \\
(36)\end{array}$ & $\begin{array}{c}7 \\
(7)\end{array}$ & $\begin{array}{c}9 \\
(8)\end{array}$ & $\begin{array}{c}25 \\
(21)\end{array}$ \\
\hline $\begin{array}{l}\text { Mean age } \\
\text { (Range) }\end{array}$ & $\begin{array}{c}75 \\
(54-88)\end{array}$ & $\begin{array}{c}74 \\
(54-86)\end{array}$ & $\begin{array}{c}76 \\
(69-88)\end{array}$ & $\begin{array}{c}75 \\
(60-88)\end{array}$ \\
\hline $\begin{array}{l}\text { Female } \\
\text { (\% of group ) }\end{array}$ & $\begin{array}{c}20 \\
(49 \%)\end{array}$ & $\begin{array}{c}(57 \%) \\
4\end{array}$ & $\begin{array}{c}12 \\
(44 \%)\end{array}$ \\
\hline
\end{tabular}

* Reason for non- completion of second interview: 3 increasing frailty so declined interview; 1 not able to contact; 1 moved out of area. 